\title{
Review
}

\section{The wellbeing of elderly people during the COVID-19 pandemic: A narrative review}

\author{
Maria Gayatri* \\ Badan Kependudukan dan Keluarga Berencana Nasional, Indonesia
}

Received 12 June 2021

Accepted 4 October 2021

Pre-press 26 October 2021

Published 13 April 2022

\begin{abstract}
.
BACKGROUND: Quarantine and social distancing are important to avoid spreading the coronavirus. Being active, healthy and happy is a central part of managing daily challenges.

OBJECTIVE: The objective of the study was to improve understanding regarding the wellbeing of the elderly during COVID-19 pandemic.

METHODS: For the literature review, keywords such as wellbeing and COVID-19 were searched for associations with terms such as elderly, ageing and old people. Only research published in peer-reviewed journals and written in English was considered in this study. The studies included in the analysis were only those published between the start of the pandemic and April 2021.

RESULTS: From a total of 75 searches, eight studies fit the inclusion criteria. Elderly people are the population group most vulnerable to COVID-19, which threatens their lives and wellbeing. Technology such as artificial intelligence can maintain the wellbeing of the elderly. Lockdown, the lack of social interaction and the limited access to medications and health facilities can worsen the physical and mental health and the psychological wellbeing of the elderly. Conclusion: It is important to highlight elderly care and mitigation programmes related to physical activities and cognitive psychology to prevent mental and functional decline in older people. Further studies should focus on their quality of life and the wellbeing.
\end{abstract}

Keywords: COVID-19, elderly, outbreak, pandemic, wellbeing

\section{Introduction}

The coronavirus continues to spread worldwide. As of mid-2021, it has infected more than 120 million people and has resulted in more than 2.5 million deaths [1]. COVID-19 is caused by the severe acute respiratory syndrome coronavirus 2 (SARS-CoV-2).

Social isolation and loneliness are a public health issue, especially among elderly people, because they impact quality of life and physical and mental health $[2,3]$. During social distancing, people try to stay at home, isolate themselves and avoid meeting family, relatives, friends or medical professionals, except

\footnotetext{
*Corresponding author: Maria Gayatri, Badan Kependudukan dan Keluarga Berencana Nasional, Indonesia, E-mail: maria.gayatri.bkkbn@gmail.com.
}

for reasons of emergency. Quarantine, lockdown and social distancing were important in slowing down the spread of the coronavirus.

Remaining active, healthy and happy can be daily challenges for the elderly during the pandemic. Life expectancy has been increasing with the result that some older people live on their own even though they have serious diseases [4]. Moreover, elderly people have a higher risk of contracting COVID-19, which can result in severe illness that can complicate their situation and increase their dependence on others, including family members, health providers and caregivers. The elderly make up a significant percentage of COVID-19 fatalities [5].

The outcome of the study was that wellbeing is important. Wellbeing is a feeling which is more than just happiness [6]. Based on the Merriam-Webster's 
Collegiate Dictionary, wellbeing is defined as 'the state of being happy, healthy or prosperous'. Wellbeing is defined as developing as an individual, feeling satisfied and contributing to society [6]. In accordance with the World Health Organization [7] and in relation to the definition of health, Wilcock proposed that there are three dimensions of wellbeing: physical, mental and social wellbeing [8]. Parameters such as life satisfaction, personal development and social wellbeing are used to measure wellbeing overall [6]. Mental wellbeing is characterised by better sleep quality, reduced depression and anxiety and other psychological outcomes [9]. The objective of this review was to improve understanding regarding the wellbeing of the elderly during COVID-19 pandemic.

\section{Materials and methods}

\subsection{Search strategy}

This study was a narrative review in which works of literature in English were evaluated using an electronic search strategy and the PubMed, MEDLINE, Cochrane Database of Systematic Reviews, Scopus, PsycINFO and Google Scholar databases. These were searched both manually and by means of a web engine, focusing on specific keywords: wellbeing, welfare, mental health, pandemic, outbreak and COVID-19 associated with elderly, ageing, older adults and old people. The keywords chosen for evaluation in the PubMed database were selected in accordance with the medical subject headings (MeSH) system. In a hierarchy called a tree, MeSH concepts are grouped, with more specific concepts arranged under broader terms [10]. The use of the MeSH terms expanded and optimised the search strategy it [10]. Search results were exported to Mendeley Desktop version 1.19.8 to remove duplicates from the analysis.

\subsection{Inclusion and exclusion criteria}

The inclusion criteria were as follows: studies with a sample of people aged 60 years or older, studies that analysed the wellbeing of elderly people in relation to mental health and physical activity, studies published in peer-reviewed journals and written in English and studies published between the start of the pandemic and April 2021. In this review, we included obser- vational, prospective and clinical trials, case-control studies, cross-sectional studies and existing data analysis. The exclusion criteria were review studies and theoretical papers that did not mention the specifics of the respondents.

From a total of 75 searches, eight studies met the inclusion criteria. The full text of each article was obtained either by retrieval from one of the databases or by requesting it from the authors. Only studies for which the full text could be obtained were included in the analysis. The scientific content was used to categorise the posts.

\section{Results}

Figure 1 summarises the search strategy. The search identified 75 articles that examined the wellbeing in older people during the COVID-19 pandemic. During the first and second stages, the articles were screened based on titles and abstracts, the inclusion criteria and duplications with other studies. During this step, 15 studies were selected, and the accessibility of their full-text was then checked. Following the screening process, only eight studies were included in the analysis [11-18].

The eight studies were either cross-sectional, randomised control, or qualitative studies including interviews (Table 1). All participants were aged 60 or older. Elderly people are the population group most vulnerable to COVID-19, which threatens their lives and wellbeing, and clinical research has shown that they are also the most frequently affected by the disease [19]. Technology such as artificial intelligence can maintain the wellbeing of the elderly, which will increase their longevity. Lockdown, lack of social interaction and the restricted access to medication and health facilities can worsen their physical and mental health and their psychological wellbeing.

Loneliness, stress, depression, anxiety, sleep disturbance and suicidal ideation symptoms are experienced by the elderly during the pandemic. Moreover, some may experience brain activity problems, such as the inability to focus, remember, recall details or multi-task. Gait disturbance, which affects the quality of walking, is also frequently experienced among the elderly along with dementia due to physical distancing and discontinuation of rehabilitation care. Physical activities, such as gardening, benefit the physical and mental health of elderly people. 


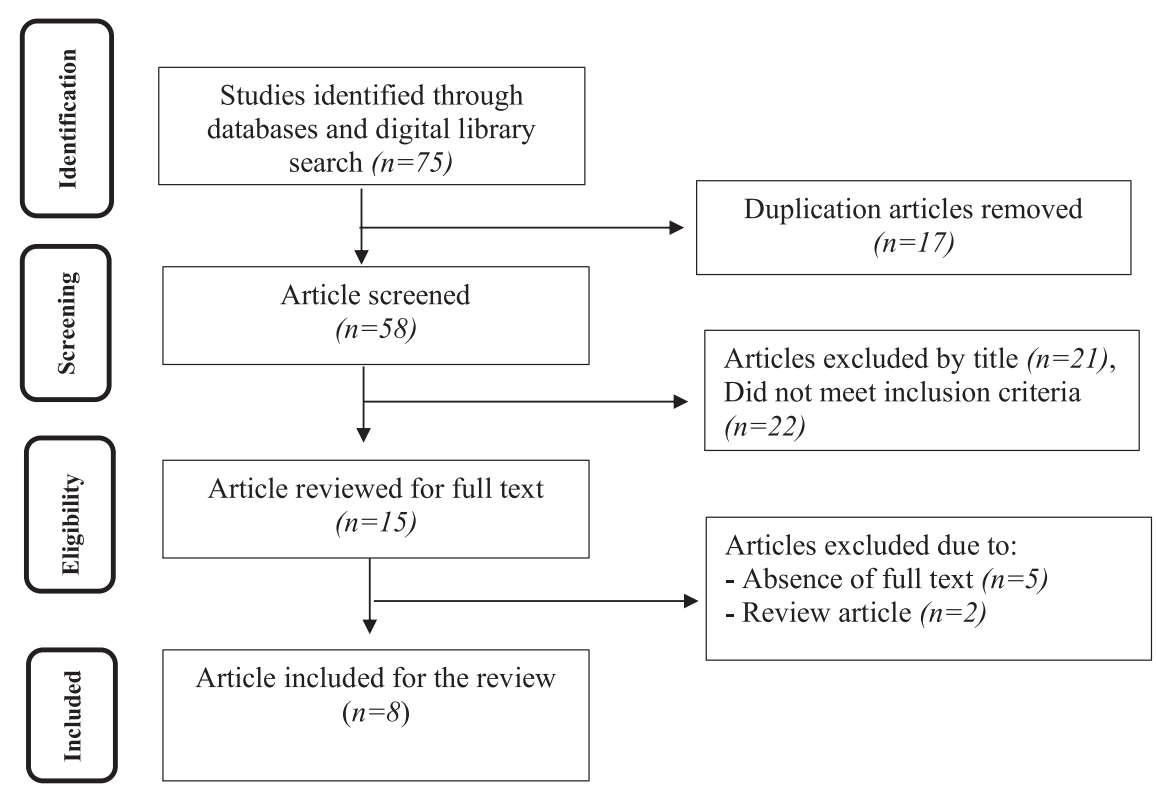

Fig. 1. Flow diagram for the selection of the studies included in the review.

\section{Discussion}

During the pandemic, older adults can face many challenges, but the majority are preventable. The pandemic has alarming implications for the wellbeing of the elderly; these are related to their health and their emotional, psychological and social functioning. Mental wellbeing is related to several parameters, including emotions, purpose in life, accomplishments, physical and mental health and interpersonal relationships [20]. The mental wellbeing of older people requires special attention because of their vulnerability and is classified as a potential public health issue, especially during COVID-19. Wellbeing is negatively affected by stress, depression, anxiety and a worse immune system and results in socioeconomic hardship [21].

Older people have a higher vulnerability to COVID-19 infection because of their weakened immune system and chronic underlying diseases $[11,12]$. Elderly people, especially those with preexisting chronic comorbidities, such as respiratory diseases, diabetes mellitus, cardiovascular diseases and renal failure, have a higher risk of COVID-19 infection and subsequent mortality [22-24].

Home confinement and isolation may cause physical and mental health issues within the geriatric population, especially for those who have limited access to communication and internet connections [23]. The pandemic limited the access of the elderly to routine interventions such as therapeutic therapy [23].

The high mortality and rapid transmission of COVID-19 increase stress, fear, frustration, confusion, anxiety, depression, difficulties with sleep, psychiatric symptoms, the risk of mental health problems and suicidal ideation symptoms, particularly among elderly people $[11,15,23,25,26]$. Stress may arise from fear of being ill, uncertainty about the disease, scarcity of personal protective equipment, limited access to medical protection, financial losses and the loss of loved ones as a result of COVID-19 $[11,25]$. Physical activity, wellbeing, quality of sleep and cognitive functioning may also be restricted by the pandemic $[13,26]$.

The incidence of stress or other psychological symptoms may impact the immune system [21]. Moreover, the elderly may experience psychological symptoms of dementia because of the pandemic and the isolation [26]. The elderly are vulnerable to wellbeing challenges during the pandemic, such as frailty, loneliness/social isolation, severe illness, cognitive impairment, psychological restriction, misconceptions about information, lack of access to COVID-19 testing, psychosocial vulnerability, addiction disorders and the challenges involved in connecting digitally with others [22]. Home confinement, social isolation and social disconnection aggravate the risk of anxiety and depression among the elderly [3]. 
Table 1

Characteristics of included studies

\begin{tabular}{|c|c|c|c|c|c|c|}
\hline No & Study & Country/Region & Study design & Outcome & Sample size & Results \\
\hline 1 & [11] & Brazil & $\begin{array}{l}\text { Self-assessment in a } \\
\text { clinical sample of } \\
\text { psychogeriatric } \\
\text { patients }\end{array}$ & $\begin{array}{l}\text { Psychological } \\
\text { and } \\
\text { behavioural } \\
\text { symptoms }\end{array}$ & 72 participants & $\begin{array}{l}\text { - The psychological distress of } 37.7 \% \text { of patients } \\
\text { worsened and } 20.8 \% \text { of patients showed new } \\
\text { mental syndromes related to the pandemic. } \\
\text { - The elderly reported sleep disorders, such as } \\
\text { insomnia, inadequate sleep, or drowsiness } \\
\text { throughout the day. } \\
\text { - Mood symptoms reported by the elderly } \\
\text { consisted of anxiety, depression and dysphoric } \\
\text { symptoms. } \\
\text { - Neuropsychiatric symptoms reported by the } \\
\text { elderly, especially by those with } \\
\text { neurocognitive disorders, consisted of } \\
\text { depression, anxiety, apathy, irritability, and } \\
\text { nocturnal behaviours. }\end{array}$ \\
\hline 2 & [12] & China & $\begin{array}{l}\text { Cross-sectional by } \\
\text { self-developed } \\
\text { questionnaire }\end{array}$ & $\begin{array}{l}\text { Psychological } \\
\text { status } \\
\text { among older } \\
\text { people }\end{array}$ & $\begin{array}{l}1556 \\
\text { participants }\end{array}$ & $\begin{array}{l}\text { - Almost } 40 \% \text { of the elderly experienced anxiety } \\
\text { and depression. } \\
\text { - Age is not related to the prevalence of } \\
\text { psychological changes among the elderly. } \\
\text { - Some psychological interventions are needed, } \\
\text { such as focusing on psychological attention, } \\
\text { physical and mental health, psychological } \\
\text { counselling, online consultations and visiting } \\
\text { health care professionals. }\end{array}$ \\
\hline 3 & [13] & Belgium & $\begin{array}{l}\text { Cross-sectional by } \\
\text { online survey }\end{array}$ & $\begin{array}{l}\text { Wellbeing and } \\
\text { cognitive } \\
\text { functioning } \\
\text { among the } \\
\text { elderly }\end{array}$ & $\begin{array}{l}262 \text { male and } \\
377 \text { female } \\
\text { adults aged } \\
65 \text { or older }\end{array}$ & $\begin{array}{l}\text { - During the pandemic, older people are reported } \\
\text { to have a substantial decline in physical } \\
\text { activity, a reduced sleep quality and a decrease } \\
\text { in their wellbeing that is linked to depression. } \\
\text { - About } 10 \% \text { of the participants reported an } \\
\text { increase in brain activity problems, such as the } \\
\text { inability to focus, remember, recall details or } \\
\text { multi-task. } \\
\text { - The pandemic had a major effect on the mental } \\
\text { health of the elderly. } \\
\text { - Depression among elderly people was related } \\
\text { to life dissatisfaction during the } \\
\text { COVID-19pandemic. }\end{array}$ \\
\hline
\end{tabular}


Randomised, controlled study

the United

States
Semi-structured,
qualitative interview

Argentina
Cross-sectional with questionnaire survey

Respiratory
rehabilita-

tion

Pre-existing,

major

depressive

disorder

Behavioural

symptom

elderly

dementia people with
72 participants aged 65 or older

73 participants aged 60 or older
119 family caregivers of elderly people with dementia
- The anxiety level decreased after receiving six weeks of respiratory rehabilitation.

- The respiratory function of the participants improved after receiving six weeks of respiratory rehabilitation.

- Older people are more afraid of contracting the virus than being isolated.

- Older people show resilience facing the stress of physical distancing.

- Virtual communication by phone and video calls with families and friends helps the elderly to mitigate the effects of social distancing and social isolation.

- The quality of life has deteriorated.

- The pandemic may harm their mental health

- It is essential to provide the elderly with education about the pandemic to preserve their mental wellbeing.

- Older adults with dementia experience anxiety, depression, insomnia and gait disturbance because of physical distancing and the discontinuation of rehabilitation services.

- Home confinement and quarantine restricted the use of rehabilitation services.

- Behavioural symptoms, such as anxiety, depression and insomnia among the elderly with dementia deteriorate and affect their quality of life.

- The use of technology assists caregivers to interact actively and provide emotional support and guidance to the elderly with dementia.

- Social engagements and medical counselling are needed to help the elderly deal with potential problems during the pandemic.

- Telemedicine and telehealth services are essential for medical counselling and to prevent unnecessary travel. 
Table 1

(Continued)

\begin{tabular}{|c|c|c|c|c|c|c|}
\hline No & Study & Country/Region & Study design & Outcome & Sample size & Results \\
\hline 7 & [17] & $\begin{array}{l}33 \text { countries } \\
\text { in Europe, } \\
\text { North } \\
\text { Africa, } \\
\text { Western } \\
\text { Asia, the } \\
\text { Americas }\end{array}$ & $\begin{array}{l}\text { Cross-sectional with } \\
\text { international online } \\
\text { survey }\end{array}$ & $\begin{array}{l}\text { Mental } \\
\text { wellbeing in } \\
\text { older adults }\end{array}$ & $\begin{array}{l}517 \\
\quad \text { participants } \\
\text { from various } \\
\text { countries }\end{array}$ & $\begin{array}{l}\text { - Mental wellbeing, sleep quality and physical } \\
\text { activities are decreased during COVID-19 } \\
\text { lockdowns. } \\
\text { - Decreased sleep quality and physical activities } \\
\text { negatively impact the mental wellbeing } \\
\text { between pre-lockdown and during lockdown. }\end{array}$ \\
\hline 8 & [18] & Scotland & $\begin{array}{l}\text { Cross-sectional with } \\
\text { online survey }\end{array}$ & $\begin{array}{l}\text { Physical and } \\
\text { mental } \\
\text { wellbeing } \\
\text { among older } \\
\text { adults }\end{array}$ & $\begin{array}{l}171 \\
\text { participants } \\
\text { aged } 70 \text { or } \\
\text { higher }\end{array}$ & $\begin{array}{l}\text { - Home gardening and relaxing in the garden } \\
\text { improved the physical, emotional and mental } \\
\text { health and the sleep quality. } \\
\text { - Outdoor activities have a positive effect on the } \\
\text { physical and psychological health, the } \\
\text { longevity and the wellbeing of elderly people. } \\
\text { - Home gardening is related to physical } \\
\text { activities, the direct interactions with nature, } \\
\text { the direct exposure to sunshine as a natural } \\
\text { source of vitamin D, fresh air and interactions } \\
\text { with neighbours while maintaining proper } \\
\text { social distancing protocols. }\end{array}$ \\
\hline
\end{tabular}


Respiratory rehabilitation training, which includes breathing exercises, such as airway clearance techniques and the exercise of respiratory muscles, is needed for COVID-19 patients to sustain physical functioning and to facilitate psychological reconstruction [27]. The emotional wellbeing of the elderly is ignored because the attention of government, health providers and society is primarily focused on precautionary steps and medication [22].

Interventions, such as community activities through social interactions, are needed to improve the quality of life of older adults who experience loneliness. Moreover, a randomised control trial study in China involving 72 patients aged 65 or older who were diagnosed with COVID-19, has shown that the intervention of a six-week respiratory rehabilitation can not only improve the quality of life and respiratory function but can also reduce anxiety among elderly patients with COVID-19 [14]. Caring for the health and wellbeing of the elderly is important during this pandemic [22].

COVID-19 has shown the importance of digital literacy for the elderly. Digitisation among the elderly has benefits, such as reducing sleep disorders, improving psychological wellbeing and increasing social interactions and activities [22]. Senior citizens need to utilise digital technologies and telemedicine during the pandemic to cope with problems related to their health and psychological and mental wellbeing. Digital technologies can educate the elderly and provide support and counselling in the form of therapeutic interventions and psychological services $[11,28,29]$. Moreover, social support through online platforms such as WhatsApp, Twitter and Facebook, or online choirs and online religious ceremonies may increase the social interactions between the elderly and other people [13, 30]. Using digital technologies such as telephones or video calls may reduce the loneliness caused by physical distancing [31].

The elderly who live alone, have a sensory or cognitive disability, or are institutionalised are especially vulnerable during the pandemic [22]. Loneliness can worsen the wellbeing and mental health of elderly people $[26,32]$. A study shows that loneliness among the elderly is associated with physical and mental health problems, such as high blood pressure, cardiovascular disease, depression and the decline of cognitive abilities [2].

Loneliness is a risk factor for the wellbeing of the elderly because of the lack of commonality or connectedness with others [30]. Loneliness harms the physical and mental wellbeing of elderly people [30].
Especially during isolation, it may lead to anxiety, cognitive dysfunction and depression [23, 30]. It is linked with the need for medical consultation using health care services $[2,32]$ and is associated with morbidity, leading to more frequent visits to physicians, not only for medical reasons but also to receive social support from doctors [2]. Elderly people experience limitations, and society must acknowledge their dependence and work to empower them.

Physical activity is associated with increased wellbeing among the elderly [9]. Regular and frequent exercise has a positive effect on depression and improves positive wellbeing and vitality, although if too frequent, it can have a negative effect, increasing the risk of injury [33].

During these difficult times, it is important to intervene holistically, to mitigate the negative consequences of isolation and loneliness and to increase the wellbeing of the older population. Community interventions, such as promoting healthy lifestyles, encouraging mental wellbeing, improving the knowledge of technological, health-promoting initiatives, helping older people to engage with technologies, providing psychological counselling (or online consultation) and offering advice on how to take care of their physical and psychological health during the pandemic, may reduce mental wellbeing problems among the elderly.

This study analyses the wellbeing of the elderly based solely on physical activity and mental health, while the social dimension of wellbeing is not explored in this study. Therefore, it is recommended for future scholars to look for the social dimension of wellbeing in older people during the COVID-19 pandemic.

\section{Conclusion}

COVID-19 can decrease the wellbeing of the elderly because they are the most vulnerable population group. The wellbeing of the elderly needs special attention from society. It is important to highlight elderly care and mitigation programmes related to physical activity and cognitive psychology, which prevent mental and functional decline in older people. Further studies should focus on the quality of life and the wellbeing of older people during the pandemic. Providing medical services and social activities for the elderly is essential for preserving their mental wellbeing and improving their quality of life during the COVID-19 pandemic. 


\section{Acknowledgments}

The author has no acknowledgments.

\section{Funding}

The author reports no funding.

\section{Conflict of interest}

The author has no conflict of interest to report.

\section{References}

[1] Worldometers. COVID-19 Coronavirus Pandemic, https:// www.worldometers.info/coronavirus/ (2021).

[2] Gerst-Emerson K, Jayawardhana J. Loneliness as a public health issue: The impact of loneliness on health care utilization among older adults. Am J Public Health 2015;105:1013-1019.

[3] Armitage R, Nellums LB. COVID-19 and the consequences of isolating the elderly. Lancet Public Heal 2020;5: e256.

[4] Petretto DR, Pili R. Ageing and COVID-19: What is the role for elderly people? Geriatrics 2020;5:1-4.

[5] Omori R, Matsuyama R, Nakata Y. The age distribution of mortality from novel coronavirus disease (COVID-19) suggests no large difference of susceptibility by age. Sci Rep 2020;10:1-9.

[6] Marks N, Shah H. A well-being manifesto for a flourishing society. J Public Ment Health 2004;3:9-15.

[7] World Health Organization. Definition of health, http:// www.who.int/aboutwho/en/definition.htm (2001, accessed 2 February 2020).

[8] Wilcock AA, van der Arend H, Darling K, et al. An exploratory study of people's perceptions and experiences of well being. Br J Occup Ther 1998;61:75-82.

[9] Kadariya S, Gautam R, Aro AR. Physical Activity, Mental Health, and Wellbeing among Older Adults in South and Southeast Asia: A Scoping Review. Biomed Res Int;2019. Epub ahead of print 2019. DOI: 10.1155/2019/6752182.

[10] Ecker E, Skelly A. Conducting a winning literature search. Evid Based Spine Care J 2010;1:9-14.

[11] Forlenza O V., Stella F. Impact of SARS-CoV-2 pandemic on mental health in the elderly: Perspective from a psychogeriatric clinic at a tertiary hospital in São Paulo, Brazil. Int Psychogeriatrics 2020;32:1147-1151.

[12] Meng H, Xu Y, Dai J, et al. Analyze the psychological impact of COVID-19 among the elderly population in China and make corresponding suggestions. Psychiatry Res 2020;289:112983.

[13] De Pue S, Gillebert C, Dierckx E, et al. The impact of the COVID-19 pandemic on wellbeing and cognitive functioning of older adults. Sci Rep 2021;11:1-11.

[14] Liu K, Zhang W, Yang Y, et al. Respiratory rehabilitation in elderly patients with COVID-19: A randomized controlled study. Complement Ther Clin Pract; 39. Epub ahead of print 2020. DOI: https:///doi.org/10.1016/j.ctcp.2020.101166.

[15] Hamm ME, Brown PJ, Karp JF, et al. Experiences of American Older Adults with Pre-existing Depression During the Beginnings of the COVID-19 Pandemic: A Multicity, MixedMethods Study. Am J Geriatr Psychiatry 2020;28:924-932.

[16] Cohen G, Russo MJ, Campos JA, et al. COVID-19 Epidemic in Argentina: Worsening of Behavioral Symptoms in Elderly Subjects With Dementia Living in the Community. Front Psychiatry 2020;11:1-10.

[17] Trabelsi K, Ammar A, Masmoudi L, et al. Sleep quality and physical activity as predictors of mental wellbeing variance in older adults during covid-19 lockdown: Eclb covid-19 international online survey. Int J Environ Res Public Health; 18. Epub ahead of print 2021. DOI: 10.3390/ijerph18084329.

[18] Corley J, Okely JA, Taylor AM, et al. Home garden use during COVID-19: Associations with physical and mental wellbeing in older adults. J Environ Psychol 2021;73:101545.

[19] Beigel JH, Tomashek KM, Dodd LE, et al. Remdesivir for the Treatment of Covid-19 - Final Report. N Engl J Med 2020;383:1813-1826.

[20] Seligman MEP. Flourish: A Visionary New Understanding of Happiness and Well-being. New York: Free Press, 2011.

[21] Mesa Vieira C, Franco OH, Gómez Restrepo C, et al. COVID19: The forgotten priorities of the pandemic. Maturitas 2020;136:38-41.

[22] Banerjee D, D'Cruz M, Sathyanarayana Rao T. Coronavirus disease 2019 and the elderly: Focus on psychosocial wellbeing, agism, and abuse prevention - An advocacy review. J Geriatr Ment Heal 2020;7:4.

[23] Peyman N, Olyania S. Iranian older adult's mental wellbeing during the COVID-19 epidemic. Asian J Psychiatr; 54. Epub ahead of print 2020. DOI: https://doi.org/10.1016/j.ajp.2020.102331.

[24] Landi F, Barillaro C, Bellieni A, et al. The New Challenge of Geriatrics: Saving Frail Older People from the SARS-COV-2 Pandemic Infection,. J Nutr Heal Aging 2020;24:466-470.

[25] Pfefferbaum B, North CS. Mental Health and the Covid-19 Pandemic. N Engl J Med 2020;383:508-510.

[26] Parish AL. Opportunities for the advanced practice nurse in improving the wellbeing of older adults during the COVID19 pandemic. Geriatr Nurs (Minneap) 2021;42:605-607.

[27] Zhao HM, Xie YX, Wang C. Recommendations for respiratory rehabilitation in adults with coronavirus disease 2019 . Chin Med J (Engl) 2020;133:1595-1602.

[28] Yao H, Chen JH, Xu YF. Rethinking online mental health services in China during the COVID-19 epidemic. Asian J Psychiatr 2020;50:102015.

[29] Liu Y, Li J, Feng Y. Critical care response to a hospital outbreak of the 2019-nCoV infection in Shenzhen, China. Crit Care 2020;24:4-6.

[30] Brooke J, Jackson D. Older people and COVID-19: Isolation, risk and ageism. J Clin Nurs 2020;29:2044-2046.

[31] Williams CYK, Townson AT, Kapur M, et al. Interventions to reduce social isolation and loneliness during COVID-19 physical distancing measures: A rapid systematic review. PLoS One 2021;16:1-28.

[32] Ellaway A, Wood S, Macintyre S. Someone to talk to? The role of loneliness as a factor in the frequency of GP consultations. Br J Gen Pract 1999;49:363-367.

[33] Lee YJ, Hung WL. The relationship between exercise participation and well-being of the retired elderly. Aging Ment Heal 2011;15:873-881. 